\title{
MOTIVATION AND BARRIERS OF UNEPLOYED PEOPLE REGARDING THEIR PARTICIPATION IN LIFELONG LEARNING PROGRAMS: A CASE STUDY IN A PREFECTURE OF GREECE
}

\author{
Konstantinos Panagiotis Kostopoulos ${ }^{1}$, \\ Thanassis Karalis ${ }^{2 i}$ \\ ${ }^{1}$ Hellenic Open University, \\ Greece \\ 2Laboratory of Pedagogical Research and Lifelong Education, \\ Department of Educational Science and Early Childhood Education, \\ University of Patras, \\ Greece
}

\begin{abstract}
:
This article presents the results of a survey on the motivation and barriers of unemployed people regarding their participation in lifelong learning programs in a prefecture of Greece. As for the methodology followed, we selected the quantitative research, which was based on the collection of quantitative research data from 109 unemployed persons using a structured questionnaire during November and December 2019. The questionnaire used in this study was based on the PRB Questionnaire, which was slightly adjusted to fit the unemployed population. Specifically, most of the unemployed (62.4\%) who participated in this survey stated that they did not participate in any seminar, training program or educational activity related to their profession. Even lower participation rates are found in general adult education programs, with only $22 \%$ saying they have attended some educational activity. Regarding the motivation of unemployed people to participate in a vocational training program, the research participants stated that finding a job was the most important motivation. They then set priorities to be more efficient in their jobs, to increase their financial returns and to maintain their future jobs. With regard to the barriers for unemployed people to participate in a vocational training program, the most important obstacle in all questions is the cost of participation. Next in the hierarchy are the lack of information, the difficulty of moving, the lack of time due to work obligations, the lack of time for occupations and the lack of time due to family obligations.
\end{abstract}

Keywords: participation, motivation, barriers, unemployed, Greece

i Correspondence: email karalis@upatras.gr kostsopsipat@yahoo.gr 


\section{Introduction}

Adult education is increasingly recognized as a necessity in many countries. Governments are exploring ways to increase access to different types of adult education through public services, private sector, or public-private partnerships (Pont, 2004). At the same time, adults require varied learning activities. Many factors favor the development of lifelong learning programs, such as high unemployment rates in Europe, the growing recognition of the importance of human capital for economic, social and personal development, the public recognition of the large number of adults without basic skills, the population aging and migration (Wurzburg, 2005). Overall, participation in adult education varies by country, but has similar patterns. Adults with higher education levels, employees, employees in larger companies, professions with white collars and younger adults participate to a greater extent (Quarantine, 2010).

Adults are looking for educational programs mainly for professional career reasons and therefore adult education is strongly influenced by the labor market. The majority of trainees in most countries participate in lifelong learning activities for vocational purposes (continuing vocational training, initial training or on-the-job training) (Iñiguez-Berrozpe et al., 2019). Unemployment, on the other hand, is at the center of global and Greek interest for a number of reasons, which have in common, on the one hand, economic development and, on the other, the psychosocial well-being of the individual. A key pillar of all employment policies is the participation of the unemployed in lifelong learning programs, so that they can develop the necessary horizontal and vertical skills that will enable them to re-enter the labor market. Exploring aspects of lifelong learning, in particular the motivations and barriers that affect their participation in similar programs, helps to draw conclusions about the unemployed population, as well as the best educational planning of actions aimed at the specific population.

\section{Literature Review}

The relevant literature records a number of motivation factors regarding the participation in educational activities, which are related both to the general perceptions and attitudes about continuing education, and to the persons' specific needs and personal aspirations (Karalis, 2016). Starting with the Houle typology, Boshier created the EPS Scale (Educational Participation Scale) (Boshier, 1971; Boshier, 1973; Boshier \& Collins, 1985), which groups motivation factors into the following broad categories: (a) development of social relationships, (b) external expectations, (c) social contribution, (d) professional development, (e) escape from other situations, and (f) interest in knowledge. Boshier and other researchers then applied the EPS scale to different populations, with the most recent form of the scale consisting of the following seven categories: (a) improving communication skills, (b) developing social contacts, (c) educational preparation , (d) 
professional development, (e) improvement of family relationships, (f), pursuit of social stimuli, (h) interest in learning a subject (Karalis, 2013).

Respectively, on the issue of barriers to participation, the typologies of Cross (1981) and Rubenson-Desjardins (2009) are more widely accepted, which distinguish three categories of barriers: (a) Situational: these are the barriers attributed to the situation in which the adult is at a certain period and include factors such as lack of money, lack of time, child care for parents, etc. (b) Organizational/institutional: this category includes factors and processes that discourage or exclude adults, such as program schedules, admission requirements for certain types of programs, limited program offer. In essence factors related to the institutions and organizations that offer adult education programs and they regulate the institutional framework of operation of these programs. (c) Dispositional: these barriers include attitudes towards learning and perceptions that adults have about their role as learners. Rubenson-Desjardins (2013) emphasize that situational barriers are mainly related to the family or work situation of the individual, while adding liquidity and lack of information as separate categories of barriers, forming finally two main categories of barriers: individual (Dispositional, liquidity, information) and structural (Situational, institutional, liquidity, information). Specifically for the unemployed population, we find that the unemployed choose to participate in adult education programs in order to be able to find work, be more productive at work, increase their financial earnings and maintain their future job (Anderson \& Niemi, 1969; McGivney, 1994; Newton et al., 2005; Paladanius, 2007; Rubenson \& Desjardins, 2006, 2009; Roosmaa \& Saar, 2017; Seyit et al., 2018; Wincup, 2009).

Regarding the barriers to participation of the unemployed, Anderson and Niemi (1969) note that institutional barriers are important inhibitors of participation and therefore propose the active participation of the community, the change of the legislation regarding education and the organization of short educational programs, focused on the improvement of the qualifications and work skills of the unemployed. Patterson (2018) notes that institutional deterrents are the cost of education and the low flexibility of program schedules, but stresses that most of the barriers for the unemployed identified are situational. Jones and Field (1989) found that short enrollment times, long waits for a program to start, and distance prevented the unemployed from participating. Rubenson \& Desjardins (2006, 2009), after analyzing a large number of relevant surveys from EU Member States, find that institutional barriers are more common among the unemployed and the handworkers. McGivney (1994) and Newton et al. (2005) conduct research reviews of adult and part-time education and training programs in the UK and note that the unemployed faced the barrier of the cost of participating in training programs. Also depending on the age of the participant, important factors may include the availability and provision of care, the coverage of transportation costs, the flexibility of training and the availability or non-availability of funding for the program.

In Greece, the review of the literature shows that in Greece no extensive research has been implemented with the unemployed, but all research efforts have focused on either the general economically active population or specific professional groups. 
Reference to the unemployed is found only in the nationwide longitudinal survey conducted by the Labor Institute of Trade Union Confederation of Greece (INE GSEE) and the Institute of Small Enterprises of Union of Craftsmen and Merchants (IME GSEVEE) regarding the motivations and barriers to participation of adults in lifelong learning (Karalis, 2018). The survey was conducted in 2011, 2013, 2015 and 2016 and confirmed the low participation of the unemployed, as only one out of fifteen unemployed participates in lifelong learning activities, while the unemployed show significantly lower participation than the other categories (employed and self-employed). Also, the unemployed attend longer programs in duration than the other categories, which happens due to the fact that most programs are subsidized and usually have a relatively long duration (as cited above). The most important motivations for the unemployed are those related to the profession and in particular the increase of financial earnings, finding a job, keeping the job, better performance at work and the acquisition of new knowledge. The most important barriers to participation for the unemployed are the cost of participation, lack of information, difficulty in transportation, lack of time to care for children and the implementation of seminars at hours and days that it is not possible for the unemployed to attend.

Also, INE GSEE in collaboration with European partners from three countries (2020) conducted a qualitive survey of low-skilled unemployed over 45 years in Greece, Bulgaria, Spain and Italy. The main conclusions of the research include the finding that the most important motivations for the unemployed are those related to the profession and in particular finding a job and improving professional qualifications, while then the need for lifelong learning is also identified. The most important barriers to participation for the unemployed are the cost of participation, lack of information and lack of appropriate qualifications.

\section{Material and Methods}

Main aim of this survey is the investigation of the motivation and the barriers of unemployed people (following the typologies of Cross and Rubenson-Desjardin) regarding their participation in lifelong learning programs in a specific Prefecture of Greece, which is Achaia. This Prefecture belongs to Western Greece and is characterized by very high unemployment rates, as the unemployed number for 2/11/2019 is 44,753 people (OAED, 2019). The highest unemployment rates are among women and among the unemployed aged 36-45. Most unemployed $(23,263)$ are in search of work for over 12 months, while in terms of educational level the majority of unemployed are graduates of Primary and Secondary Education. In addition, the Region of Western Greece, to which the Prefecture of Achaia belongs, is in the second place in Greece at unemployment rates (23.9\%) (HSA, 2019).

The main objectives of the research are the following: a) Investigation of the participation rate of the unemployed of the sample in educational programs of lifelong learning b) Description of lifelong learning programs on a range of topics (topic, duration, 
nature, cost, implementing body, methodology and degree of satisfaction) c) Investigation of the motivations and barriers of participation of the unemployed in lifelong learning activities related to the profession d) Detection of the desire to participate in future programs e) Collection of individual and demographic data $f$ ) Formulation of proposals for increasing the participation of the unemployed in lifelong learning activities

To achieve the above objectives, in terms of methodology, we selected the quantitative research and specifically the survey research, which was based on the collection of quantitative research data from 109 unemployed in a short period of time using a structured questionnaire. The questionnaire, used in this research, was based on the PRB Questionnaire of Karalis $(2013,2018)$, which underwent minor adjustments to be adapted to the unemployed population.

\section{Results and Discussion}

Most unemployed (62.4\%) of the Prefecture of Achaia who participated in the present survey stated that they have not participated in any seminar, training program or educational activity related to their profession. Regarding the issue of participation or not, we used as a criterion of differentiation, the period of one and five years, according to the time intervals used by Karalis $(2013,2018)$, in which the participant is defined as the one who has participated in at least one program of any type in the last five years. Only 41 persons (37.6\%) stated that they have attended any educational activity. Even lower participation rates are found in general education programs, as only 24 persons (22\%) stated that they have attended any educational activity. These data are close to the average participation of the unemployed in the EU concerning lifelong learning programs for 2016, which amounts to $32.2 \%$. This percentage is significantly different from the $10.5 \%$ of Greece according to the Eurobarometer, which, however, includes all lifelong learning programs, those related to the profession and general education at a different time horizon (in the 4 last weeks) (Eurostat, 2019).

In terms of participation for professional reasons, $70.7 \%$ of the unemployed took part in a program in the last five years, $29.3 \%$ in the last 5 years and only $8.3 \%$ took part in any activity in the last year. Karalis (2018) points out that the unemployed show significantly less participation than in other occupational categories, with only $6.9 \%$ having attended at least one program related to the profession in the last year. As for the unemployed participants in general education programs, $83.3 \%$ participated in an educational activity during the last five years and only $16.7 \%$ participated in the last year. Regarding the number of vocational training programs that the unemployed have attended during the last five years, 58.6\% of people have attended only 1 program and only $27.6 \%$ have attended more than 3 seminars. The average number of attendance seminars was 2.52 seminars over the last five years. The average number of general education activities was 1.79 seminars over the last five years. 
Regarding the other characteristics of the unemployed, the following conclusions emerge for those who state that they have participated at least once in the past in a program related to the profession: a) Women participate more than men b) Most of the participating unemployed are over 40 years old c) Marital status does not play any specific role in terms of participation d) The lack of children facilitates participation e) Unemployment duration does not play a role f) Higher education graduates participate more than the other categories, with participation rates increasing as the educational level rises g) Family income does not play any role in participating in this sample. In particular, regarding the participation of individuals in general education / training programs during the last five years: a) Most of the participating unemployed are over 40 years old. b) Graduates of higher education participate more than other categories, with participation rates increasing as the educational level rises. c) In the other variables (gender, marital status, number of children, unemployment duration and family income) there are no significant differences between the subcategories.

Boeren (2011) based on OECD and EU Eurobarometer reports, distinguishes 6 groups of adults in terms of their chances of getting involved in education programs, and points out that the unemployed aged 26-45, the highly educated and the more qualified unemployed have higher participation rates. However, the higher participation of women compared to men is a new fact in the unemployed population. According to OECD reports (as cited in Edwards, Sieminski \& Zeldin, 1993), some groups of women (housewives and mothers) find it difficult to participate in lifelong learning programs.

As for the special features of the programs related to the profession, the unemployed mostly attend educational activities related to Administration-Economics and Humanities. These subjects also coincide with the professional sectors with the highest unemployment rates (HSA, 2019) and therefore the unemployed attend these programs in order to improve their work skills in sectors that are mainly affected by unemployment. We point out that the largest percentage of unemployed for the first quarter of 2019 (23.1\%) according to HSA, worked in the hotel and catering sector. Regarding the profession of their previous work, the largest percentage $(31.8 \%)$ were employed in the provision of services or as salespersons.

The intensity of the participation during the last five years is depicted with the indicator that refers to the total duration of the hours of the seminars attended by the participants. As for the duration of the programs related to the profession, the average duration is for the first program 166.48 hours, for the second 169.67 hours and for the third 143.44 hours. Therefore, their duration exceeds an average of 100 hours for all three programs. For general education programs, the average duration is 87.54 hours. Karalis notes (2018) that the unemployed are those who attend programs of longer duration compared to the other categories (54.32 hours for 2016 and 78 hours for 2015). The reason for this, is related to the need to find a job, which leads the unemployed to attend seminars of several hours in order to update their knowledge and to be trained in another field or profession. This hypothesis is also supported by the fact that the individuals in the sample participated on their own initiative in the seminars, which to a large extent 
had tuition fees and private implementers, in order to cover their specific educational needs, even if they had to cover the cost (all three programs had tuition fees, which costed over $100 €$ ). Participation in subsidized programs was low, especially for those who attended more than one seminar. These data prove that the unemployed attend programs with a relatively long duration, which however are not subsidized and this is a new element compared to the past, when according to Karalis (2018) the unemployed attended more subsidized programs than the other categories, which usually lasted relatively long.

The participants attended primarily face to face programs and secondly distance learning. In terms of the degree of satisfaction with key parameters of the program, most unemployed said they were more satisfied with the trainers, the analytical content, the organization, the training methods and the fulfillment of their needs.

The low participation in educational activities creates a training deficit and therefore possible means of substituting participation in adult education activities should be identified, which could be sought in non-formal education institutions and mechanisms (such as work, family), the media, libraries, the internet, organizations and citizens' associations) (Karalis, as cited above).

As for the alternative sources of learning for the unemployed in relation to the profession, the most important source of learning is the internet and the second most important is colleagues, followed by the study of relevant books or magazines and knowledge updating during the work. In terms of demographic characteristics, no differences were found in the sources of learning within the categories, except for people aged 31-40, who stated that the second most important source of learning was the daily information at work. Therefore, in addition to the undeniable importance of the internet, non-formal on-the-job training (on-the-job information and information from other colleagues) remains an important training mechanism for the unemployed. These data are in line with the research of Karalis (as cited above), in which the most important source of learning is the internet, followed by colleagues, daily updates at work and the study of relevant books or specialized magazines. Although participation in lifelong learning activities is low, the vast majority of the unemployed (93.6\%) express a desire for future participation in a lifelong learning program in the next 12 months, which strengthens the hypothesis that the unemployed recognize the need for their retraining either to enter the labor market or to remain in it.

Regarding the motivations of the unemployed to participate in an educational program related to the profession, the participants in the research stated that the most important motivation is finding a job. Their second priority is to be more efficient in their work, increase their financial earnings and maintain their future job. Low in the choices of the unemployed are the factors that belong to the groups of personal family life and social participation. Therefore, the motivations are mainly related to the professional upgrading of the qualifications of the unemployed, which proves the emotional tension the people experience and that finding a job and keeping it, is an immediate priority for them. These results are in line with the research of Karalis (as cited above), who states 
that unemployed note as the most important motivations, those related to the professional upgrading and secondly the motivation to learn new things. These findings are also confirmed by foreign studies related to the unemployed (Anderson \& Niemi, 1969; McGivney, 1994; Newton et al., 2005; Paladanius, 2007; Rubenson \& Desjardins, 2006, 2009; Roosmaa \& Saar, 2017; Seyit et. al., 2018; Wincup, 2009). Also, no significant differences are found in the choice of the most important motivation in relation to the demographic variables and therefore finding a job is the most popular motivation in all cases.

Regarding the barriers to participation of the unemployed, the most important obstacle in all questions is the cost of participation. This barrier is explained on the one hand by the financial crisis and on the other by the personal financial difficulty of the unemployed due to unemployment and lack of financial resources. Other barriers are the lack of information, difficulty in transportation, lack of time due to work obligations and lack of time due to family obligations. Therefore, the unemployed in the sample propose the institutional barriers, followed by the situational and especially those related to family and work obligations and the consequent lack of time. Unexpected finding is the lack of information, a barrier that is very common, although the unemployed mention that internet is their main source of information. Therefore, the use of the internet does not automatically imply the development of appropriate information retrieval skills.

The above findings regarding the barriers to participation in the unemployed population are also found in the research of Karalis (as cited above), where the cost of participation is identified as the main barrier, followed by institutional barriers (lack of information, difficulty of movement, inappropriate hours and days). Anderson and Niemi (1969) note that institutional barriers are a major deterrent to participation and therefore propose active community involvement, change in education legislation and the organization of short training programs focused on improving qualifications and employment skills of the unemployed. Patterson (2018) notes that institutional deterrents are the cost of education and the low flexibility of schedule programs, but stresses that most of the deterrents for the unemployed identified in the survey, are situational. Jones and Field (1989) found that short enrollment times, long waits for a program to start, and distance prevented the unemployed from participating. Rubenson \& Desjardins (2006, 2009), after elaborating on a large number of relevant surveys from EU Member States, find that institutional barriers are more common among the unemployed and the manual workers. McGivney (1994) and Newton et al. (2005) conduct research reviews of adult and part-time education and training programs in the UK and note that the unemployed faced the barrier of the cost of participating in training programs. Also depending on the age of the individual, important factors may include the availability and provision of care, the coverage of transportation costs, the flexibility of training and the availability or non-availability of funding for the program. 


\section{Recommendations}

It is important to conduct repeated surveys on the issue of barriers and motivation for the unemployed at the national level, in order to update the research data and to identify local specificities, with the prospect of implementing respective tailored programs.

It would also be interesting to expand the research to include the views of educators and lifelong learning carriers concerning the barriers and motivation of the unemployed and compare the two populations. The purpose of this methodology would be to confirm and achieve completeness in understanding the phenomenon. Finally, more variables need to be included in future research, such as nationality, parents 'educational and financial status, participants' occupation and place of residence.

\section{Conclusion}

The unemployed person is affected in the most sensitive core of his personal situation, in his sense of individual self-efficacy, and self-confidence, feeling helpless and powerless to influence the environment, with immediate consequences of fleeing, frustration and resignation. The unemployed suffer the negative effects of unemployment, which create an increasingly established "distance" from the labor market and the processes that facilitate its integration into it. Lifelong learning could facilitate this reintegration and remove the negative consequences of lack of work. However, as it turned out, the unemployed population prioritizes finding a work and the motivation for participating in educational activities is focused almost exclusively on their professional upgrade. These motivations should be considered in relation to the institutional barriers that need to be removed or overcome. Lifelong learning programs should be targeted at this specific population, to facilitate the access of adults to participation and to meet a number of conditions, which are based on the results of this research.

The educational interventions that will significantly increase the possibilities for finding a job are a necessity. In organizing specialized training, it is necessary to utilize the experience of institutions, social partners and the scientific community of each profession in close relation to the socio-economic conditions of each region, but mainly to conduct research studies on this subject. The unemployed person expresses the desire to be educated but does not have the ability to spend on processed and constantly repeated programs. The daily exercising of career counseling to the unemployed confirms the will of the individuals to be trained in objects that aim to strengthen their professional background and offer a substantial way out of unemployment and tangible results in finding a job. The unemployed person is looking for a job to reverse the negative emotional and financial turmoil he has entered and needs sound hopes that he will succeed, and for this reason he spares no effort and financial sacrifice.

The subsidized trainings are constantly decreasing and their poor integration results, are no longer a pole of attraction for the majority of the unemployed. The implementation of voucher policies (a voucher for a training participation) in the last 
decade has resulted in the constant decline of the quality of implementation of the programs (Karalis, 2018, p.70), something that also functions as an important deterrent to the participation of citizens in educational activities. Actions aimed at the unemployed need to include internships to enable the participant to better understand the needs of the workplace and how to apply the recently acquired skills. The unemployed person suffers from financial difficulties, poor physical and mental health, loss of self-esteem and confidence, social isolation, low levels of educational performance, etc. (Kostopoulos, 2013). The constraints of unemployment in combination with the institutional barriers (cost of programs, lack of information, difficulty of transportation, inappropriate hours and days of training) deactivate every initiative of the unemployed. In this complex reality, vocational counseling is a central pillar of lifelong learning for the unemployed and should work individually and supportively, so that the individual is effectively guided in appropriate training and lifelong learning actions. This support is important to be provided in all phases of the transition to the new job.

Other issues, such as the cost of training, do not allow the complete abolition of subsidized actions, but funding agencies must set the conditions that will favor the quality of action and the use of available resources in proportion to each population. The supervising authorities need to fulfill their role and grant licenses or funding programs to objectively certified and continuously evaluated carriers. Quality must govern all stages of the educational intervention, and there could be an open platform for evaluation and publicized criticism for each program body with procedures that will ensure transparency and sound evaluation criteria and indicators. The issue of information and briefing must be addressed on the one hand with the publication of the actions and the personalized information of the unemployed themselves, such as for example through the OAED career counselors. Lack of time due to obligations brings to the fore again the need to implement flexible programs that will use mixed learning methods, while companies and employers should adopt more active roles of in-company training.

\section{About the Author(s)}

Thanassis Karalis is Professor of Lifelong Learning and Adult Education in the Department of Educational Science and Early Childhood Education at the University of Patras. He is Director of the Laboratory of Pedagogical Research and Lifelong Education, member of the Quality Assurance Unit, coordinator of the Center for Teaching and Learning at the University of Patras. For the last thirty years he has been working in the area of planning and evaluation of adult education and non-formal education programs, including more than twenty years in distance education and e-learning.

Konstantinos Panagiotis Kostopoulos is Career Counselor and Adult Educator. He has collaborated with many educational institutions and career counseling carriers as trainer, counselor and scientific coordinator. 


\section{References}

Anderson, D., \& Niemi, J. (1969). Adult Education and the Disadvantaged Adult. US Department of Health, Education \& Welfare Office of Education.

Boeren, E. (2011). Participation in Adult Education: Attitudes and Barriers. US-China Education Review A, 3, 369-382.

Boshier, R. (1971). Motivational Orientations of Adult Education Participants: A Factor Analytic Exploration of Houle's Typology. Adult Education Quarterly, 21(2), 3-26.

Cross, K. P. (1981). Adults as learners. Jossey-Bass.

Desjardins, R., Rubenson, K., \& Milana, M. (2006). Unequal Chances to Participate in Adult Learning: International Perspectives. Fundamentals of Educational Planning 83. International Institute for Educational Planning (IIEP) UNESCO.

Edwards, R., Sieminski, S., \& Zeldin, D. (1993). Adult Learners, Education and Training. Routledge.

HAS - Hellenic Statistical Authority (2019, November 1). Labor Force Survey. B' Quarter 2019. Hellenic Statistical Authority. https://www.statistics.gr/documents/20181/99d5f275-8872-941b-aa80795a10bca3cf.

Eurostat (2019, November 5). Life Long Learning Statistics Explained. Eurostat. https://ec.europa.eu/eurostat/statisticsexplained/index.php?title=Adult learning statistics\#Participation rate of adults in learning in the last 12 months.

INE-GSEE (2020). Requirements and influential factors for engaging unemployed lowskilled Adults over 45 years old in training. INE GSEE.

Iñiguez-Berrozpe, T., Elboj-Saso, C., Flecha, A., \& Marcaletti, F. (2019). Benefits of Adult Education Participation for Low-Educated Women. Adult Education Quarterly August 2019 1-25.

Jones, A. \& Field, J. (1989) Attitudes to open learning: A survey of unemployed adults, The Vocational Aspect of Education, 41(108), 21-24.

Karalis, T. (2017). Shooting a moving target: The Sisyphus boulder of increasing participation in adult education during the period of economic crisis. Journal of Adult and Continuing Education 23(1), 78-96.

Karalis, T. (2013). Barriers and motivation for the participation of adults in lifelong learning. INE-IME GSEVEE.

Karalis, T. (2018). The participation of adults in lifelong learning. Barriers and motivation for Participation (2011-2016). INE-IME GSEVEE.

Karantinos, D. (2010). Participation in lifelong learning: Trends and perspectives. In D. Vergidis \& A. Kokkos (Ed.), Adult education international approaches and Greek routes (pp. 43-62). Metaichmio Editions.

Kostopoulos, K. P. (2013). The concept of work in Orthodox monasticism as a source of inspiration for the modern working reality. (Master dissertation Thesis, Hellenic Open University). 
McGivney, V. (1994). Veronica Wasted Potential: Training and Career Progression for PartTime and Temporary Workers. National Institute of Adult Continuing Education.

Newton, B., Hurstfield, J., Miller, L., Akroyd, K., \& Gifford, J. (2005). Training participation by age amongst unemployed and inactive people. Department for Work and Pensions.

Paladanius, S. (2019, November 10). The Rationality of Reluctance and Indifference Toward Adult Education: Difficulties in Recruiting Unemployed Adults to Adult Education. New Prairie Press. http://newprairiepress.org/aerc/2007/papers/79.

Patterson, M. (2018). The Forgotten 90\%: Adult Nonparticipation in Education. Adult Education Quarterly 68(1), 41-62.

Pont, B. (2004). Improving Access to and Participation in Adult Learning in OECD Countries. European Journal of Education, 39(1), No. 1, 31-45.

Roosmaa, E. \& Saar, E. (2017). Adults who do not want to participate in learning: a crossnational European analysis of their perceived barriers, International Journal of Lifelong Education, 36(3), 254-277.

Rubenson, K., \& Desjardins, R. (2009). The impact of welfare state regimes on barriers to participation in adult education: A bounded agency model. Adult Education Quarterly, 2009(1), 187-207.

Rubenson, K., \& Desjardins, R. (2013). Participation Patterns in Adult Education: the role of institutions and public policy frameworks in resolving coordination problems. European Journal of Education, 48(2), 262-280.

Wurzburg, G. (2005). Why Economic and Financial Sustainability Matter for Lifelong Learning. European Journal of Education, 40(1), 69-91.

OAED (2019, November 2). Recorded data of registered unemployment for the Prefecture of Achaia. OAED information system. 
Creative Commons licensing terms

Authors will retain the copyright of their published articles agreeing that a Creative Commons Attribution 4.0 International License (CC BY 4.0 ) terms will be applied to their work. Under the terms of this license, no permission is required from the author(s) or publisher for members of the community to copy, distribute, transmit or adapt the article content, providing a proper, prominent and unambiguous attribution to the authors in a manner that makes clear that the materials are being reused under permission of a Creative Commons License. Views, opinions and conclusions expressed in this research article are views, opinions and conclusions of the author(s). Open Access Publishing Group and European Journal of Alternative Education Studies shall not be responsible or answerable for any loss, damage or liability caused in relation to/arising out of conflict of interests, copyright violations and inappropriate or inaccurate use of any kind content related or integrated on the research work. All the published works are meeting the Open Access Publishing requirements and can be freely accessed, shared, modified, distributed and used in educational, commercial and non-commercial purposes under a Creative Commons Attribution 4.0 International License (CC BY 4.0). 